\title{
Pharmacokinetic study of a novel oral formulation of S-adenosylmethionine (MSI- $195)$ in healthy subjects: dose escalation, food effect and comparison to a commercial nutritional supplement product
}

Beth R. Cameron, Ludvina Ferreira and I. David MacDonald*

\begin{abstract}
Background: A novel, high bioavailability oral, enteric coated tablet formulation of S-adenosylmethionine (MSI-195) has been developed for life science application. The present research reports on a Phase 1 study to (i) determine the safety of single doses of MSI-195 (ii) to determine the dose proportionality of MSI-195 at doses of 400, 800 and $1600 \mathrm{mg}$ (iii) determine the pharmacokinetics of MSI-195 compared with a commercial reference product (SAM-e Complete ${ }^{\mathrm{TM}}$ ) over $24 \mathrm{~h}$ and (iv) to determine the effect of food on the pharmacokinetic profile of MSI-195 in human subjects.
\end{abstract}

Methods: This study was a pharmacokinetic and safety evaluation of MSI-195 and a commercial comparator broken into two stages. The first stage was an exploratory single ascending dose design of MSI-195 in 8 healthy normal male volunteers. The second stage was a single dose evaluation, targeting 26 male and female volunteers at set doses of MSI-195 and commercial comparator in a cross-over design followed by a food effect study on MSI-195. Plasma samples were collected and assayed for S-adenosylmethionine using a validated HPLC method with MS/MS detection. The main absorption and disposition parameters were calculated using a non-compartmental approach with a log-linear terminal phase assumption. Statistical analysis was based on an ANOVA model or $t$ test as appropriate.

Results: MSI-195 was found to be generally well tolerated with an adverse event profile similar to the SAM-e Complete ${ }^{\text {TM }}$ comparator product. The relative bioavailability of MSI-195 was approximately 2.8-fold higher than SAMe Complete based on area under the curve (AUC) ratios for the two products and the MSI-195 formulation exposure based on AUC was found to be approximately dose proportional. There was a significant food effect for MSI-195 with a delayed time to maximum absorption $\mathrm{T}_{\max }$ going from $4.5 \mathrm{~h}$ under fasted conditions to $13 \mathrm{~h}$ under fed conditions, and area under the curve with food reduced to $55 \%$ of that seen under fasting conditions.

(Continued on next page)

* Correspondence: dmacdonald@methylationsciences.com

MSI Methylation Sciences Inc, Suite 300, 15300 Croydon Drive, Surrey, BC V3Z 0Z5, Canada

C C The Author(s). 2020 Open Access This article is licensed under a Creative Commons Attribution 4.0 International License, which permits use, sharing, adaptation, distribution and reproduction in any medium or format, as long as you give appropriate credit to the original author(s) and the source, provide a link to the Creative Commons licence, and indicate if changes were made. The images or other third party material in this article are included in the article's Creative Commons licence, unless indicated otherwise in a credit line to the material. If material is not included in the article's Creative Commons licence and your intended use is not permitted by statutory regulation or exceeds the permitted use, you will need to obtain permission directly from the copyright holder. To view a copy of this licence, visit http://creativecommons.org/licenses/by/4.0/. The Creative Commons Public Domain Dedication waiver (http://creativecommons.org/publicdomain/zero/1.0/) applies to the data made available in this article, unless otherwise stated in a credit line to the data. 
(Continued from previous page)

Conclusions: The overall conclusion was that MSI-195 was well tolerated and has markedly higher bioavailability compared with both the SAM-e Complete ${ }^{\mathrm{TM}}$ commercial product tested and, on a per mg basis, products reported in other literature.

Trial registration: ClinicalTrials.gov, identifier NCT04623034. Retrospectively registered Nov 9, 2020.

Keywords: Pharmacokinetics, Ademetionine, Adomet, S-adenosylmethionine, Formulation, Relative bioavailability

\section{Background}

S-adenosylmethionine (SAMe, generic name Adomet) is a naturally occurring, physiologically active molecule that is distributed in all body tissues. SAMe has been studied pharmacologically, with varying levels of clinical evidence supporting efficacy, in numerous indications including depression, liver disease and osteoarthritis [1-4]. More recently, the molecule is being studied pre-clinically as a potential therapeutic in oncology [5-8].

MSI-195 is a proprietary, oral formulation of SAMe that has been researched, developed and patented by Methylation Sciences. This formulation was developed and has been studied in the United States under an FDA IND in a multicenter, randomized, double-blind, placebo-controlled Phase 2 depression clinical trial (ClinicalTrials.gov NCT01912196). [9, 10]

The history of S-adenosylmethionine pharmacology began in the 1970's when it was studied as a parenteral product in Europe, and subsequently as an oral formulation [11]. More recently, oral formulations of SAMe have been commercialized in the dietary/nutritional supplement fields. Current oral formulations are enteric coated, which helps with tolerability and bioavailability however, even with that, oral bioavailability is low. Yang and co-workers determined an $\mathrm{AUC}_{0-24}$ Oral/IV ratio was determined to be $2.60 \%$ and $2.14 \%$ in men and women respectively [12].

Oral dosing of S-adenosylmethionine in clinical studies for depression is most frequently $1600 \mathrm{mg} /$ day [13]. (dosing is calculated based on the amount of the free base). To deliver that dose, 4 large tablets of approximately $1 \mathrm{~g}$ each are required. This is a significant pill burden and also comes at a significant expense.

The objectives of this clinical study were to (i) determine the safety of single doses of MSI-195 (ii) to determine the dose proportionality of MSI-195 at doses of 400, 800 and $1600 \mathrm{mg}$ (iii) determine the pharmacokinetics (PK) of MSI-195 compared with a commercial reference product (SAM-e Complete ${ }^{\mathrm{TM}}$ and (iv) to determine the effect of food on the pharmacokinetic profile of MSI-195 in human subjects.

\section{Methods}

\section{MSI-195 formulation}

The MSI-195 formulation is a novel patented [14, 15] tablet that is comprised of a core tablet, a seal coat and an enteric coat. The core contains S-adenosylmethionine Disulphate Tosylate (OmniaBios), microcrystalline cellulose, sodium starch glycolate, colloidal silicon dioxide, magnesium stearate and the GRAS excipient propyl gallate. The seal coat consists of Opadry AMB and ferric oxide and the enteric coating is Eudragit L30D55(Evonik). MSI discovered that formulations of SAM-e including propyl gallate have enhanced systemic absorption [14]. The test article used in the present study has a dosage strength of $400 \mathrm{mg}$ (based on the weight of the free base). The SAM-e counter-ions are disulfate tosylate and the overall tablet weight is approximately $1.2 \mathrm{~g}$.

\section{SAM-e complete ${ }^{\mathrm{TM}}$ commercial comparator}

The SAM-e Complete ${ }^{\mathrm{TM}}$ commercial comparator is manufactured by Pharmavite under the NatureMade ${ }^{\text {Ts }}$ brand. The dosage strength is $400 \mathrm{mg}$ (based on the free base). Total tablet weight is approximately $1 \mathrm{~g}$. Test material was purchased in the United States at Costco.

\section{Study design}

This study was a pharmacokinetics and safety evaluation of the MSI-195 proprietary S-adenosylmethionine oral dosage form and a commercial comparator consisting of two stages. (see Table 1) The first stage was an exploratory single ascending dose design of MSI-195 in 8 healthy normal male volunteers. The second stage was a more comprehensive single dose evaluation, targeting 26 male and female volunteers at set doses of MSI-195 and commercial comparator in a cross-over design followed by a food effect study on MSI-195. Further design details are listed below.

\section{Stage 1 design}

In each period of this stage of the study, ascending single doses of $400 \mathrm{mg}, 800 \mathrm{mg}$ and $1600 \mathrm{mg}$ of MSI-195 SAdenosylmethionine (SAMe) was orally administered under fasted conditions, followed by $24 \mathrm{~h}$ of blood draws at periodic intervals for the determination of plasma concentration of S-adenosylmethionine in a repeatedmeasure design. The drug administrations were separated by a wash-out of 7 calendar days. 
Table 1 Description of the test articles and dosing for the 2 stages of this pharmacokinetic study

\begin{tabular}{|c|c|c|c|}
\hline S-adenosylmethionine Test Article Name & Dosage Form/ Route of Administration & Stage 1 dosing & Stage 2 dosing \\
\hline \multirow[t]{3}{*}{ MSI-195 } & Tablet/ Oral & - 400 mg (1 x 400 mg) & • 800 mg (2 x 400 mg) \\
\hline & & • 800 mg (2 × 400 mg) & \\
\hline & & • $1600 \mathrm{mg}(4 \times 400 \mathrm{mg})$ & \\
\hline SAM-e Complete $\mathrm{TMb}^{\mathrm{TMb}}$ & Tablet/Oral & $\mathrm{n} / \mathrm{a}$ & - $1600 \mathrm{mg}(4 \times 400 \mathrm{mg})$ \\
\hline
\end{tabular}

${ }^{\mathrm{M} M S I}-195$ is Methylation Sciences' proprietary oral enteric coated tablet formulation of S-adenosylmethionine

${ }^{\mathrm{b}} \mathrm{SAM}$-e Complete ${ }^{\mathrm{TM}}$ is a commercial dietary supplement oral enteric coated tablet formulation manufactured by Pharmavite in the United States under the NatureMade ${ }^{\mathrm{TM}}$ brand

\section{Stage 2 design}

In the first 2 periods of this stage of the study, a single $800 \mathrm{mg}$ dose of MSI-195 SAMe and a single $1600 \mathrm{mg}$ dose of commercial comparator (SAM-e Complete ${ }^{\mathrm{Tm}}$ ) were orally administered under fasted conditions, in a 2way crossover design. During the 3rd period, a single $800 \mathrm{mg}$ dose of MSI-195 was administered under fed conditions to all subjects. The drug administrations were separated by a wash-out of 7 calendar days. For each dosing, subjects had periodic blood draws over a $24 \mathrm{~h}$ period to determine the plasma concentration of Sadenosylmethionine as a function of time.

\section{Study population diagnosis and main criteria of inclusion}

Male and female volunteers, non- or ex-smokers, between 21-55 years of age with a body mass index greater than or equal to 18.50 and below $30.00 \mathrm{~kg} / \mathrm{m} 2$ were included in the study. Subjects were in good health as determined by a medical history, complete physical examination (including vital signs), electrocardiogram (ECG), neurological examination and the usual clinical laboratory tests (general biochemistry, endocrinology, hematology, urinalysis) including negative $\mathrm{HIV} \mathrm{Ag/Ab} \mathrm{Combo,} \mathrm{Hepatitis} \mathrm{B} \mathrm{and}$ Hepatitis $\mathrm{C}$ tests $(\mathrm{HCV}(\mathrm{C}))$ as well as negative screening of alcohol and drugs of abuse in urine and negative pregnancy test (for female subjects).

\section{Sample collection - draw timing}

In Stage 1 of the study, 18 blood samples were collected as follows: prior to drug administration $(\mathrm{t}=0)$ and 1,2 , $3,3.5,4,4.5,5,5.5,6,6.5,7,8,9,10,11,12$ and $24 \mathrm{~h}$ after drug administration. In Stage 2 of the study, for periods under fasting conditions, the 18 blood samples were collected as follows: prior to drug administration $(\mathrm{t}=0)$ and $1,2,3,3.5,4,4.5,5,6,7,8,9,10,11,12,14$, 16 and $24 \mathrm{~h}$ after drug administration, and for the period under fed conditions, the 18 blood samples were collected as follows: prior to drug administration $(\mathrm{t}=0)$ and $1,2,3,4,5,6,7,8,9,10,11,12,14,16,18,21$ and $24 \mathrm{~h}$ post drug administration.

\section{Food administration}

Food was controlled and standardized throughout the study. The protocol required that subjects start fasting at least $10 \mathrm{~h}$ before drug administration for Stage 1 and at least $12 \mathrm{~h}$ before drug administration for Stage 2. Fasting continued for $1 \mathrm{~h}$ following drug administration in Stage 1, after which a standardized light breakfast was served. A lunch, a supper and a light snack were served at appropriate times thereafter. For Stage 2, all subjects received a standardized low-fat supper before the overnight fasting period. In the first 2 periods, fasting continued for at least $4 \mathrm{~h}$ following drug administration, after which a standardized moderate to low fat lunch was served. In the 3rd period, subjects received a standardized high-fat, high calorie meal thirty (30) minutes before drug administration. Further meals were also standardized. In each study period, blood samples were collected over a $24 \mathrm{~h}$ period for assessment of SAMe pharmacokinetics. The drug administrations were separated by at least 7 calendar days, in both stages of the study.

\section{Bioanalytical Handling of samples}

Blood samples were collected in pre-cooled $K_{2}$ EDTA Vacutainers. As soon as possible following blood collection, samples were centrifuged at a temperature of $4{ }^{\circ} \mathrm{C}$ nominal and at approximately $1500 \mathrm{~g}$ for $10 \mathrm{~min}$. A volume of $1.0 \mathrm{~mL}$ of plasma was transferred into a polypropylene culture tube containing $40 \mu \mathrm{L}$ of a solution of $10 \% \mathrm{H}_{3} \mathrm{PO}_{4}$, for analyte stability, and was vortexed for at least $5 \mathrm{~s}$. Half of the acidified plasma was then transferred into a second polypropylene tube in order to obtain 2 splits of approximately $0.5 \mathrm{~mL}$ of acidified plasma each. Samples were kept in an ice-water bath until frozen in an upright position and retained at a temperature of $-80{ }^{\circ} \mathrm{C}$ nominal or on dry ice until shipment to the analytical facility. The samples were stored frozen at $-80{ }^{\circ} \mathrm{C}$ until assayed. The time from blood sample collection to plasma aliquot storage was within $45 \mathrm{~min}$. 


\section{Method of measurement}

Plasma samples were received frozen by the analytical facility (Algorithme Pharma). The experimental samples were assayed for S-adenosylmethionine at the analytical facility using a validated HPLC method with MS/MS detection. The lower limit of quantitation and upper limit of quantitation were 10.0 and $5000.0 \mathrm{ng} / \mathrm{mL}$, respectively.

\section{Pharmacokinetic assessments}

The main absorption and disposition parameters were calculated using a non-compartmental approach with a log-linear terminal phase assumption. The trapezoidal rule was used to estimate area under the curve, and the terminal phase estimation was based on maximizing the coefficient of determination. The pharmacokinetic parameters of this trial were $C_{\max }$, (peak drug concentration) $\mathrm{T}_{\max }$, (time to peak drug concentration), $\mathrm{AUC}_{\mathrm{T}}$, (Area under the plasma concentration versus time curve from time 0 to $24 \mathrm{~h}$ ) $\mathrm{AUC}_{\infty}$, (Area under the plasma concentration versus time curve from time 0 to infinity), $\mathrm{K}_{\mathrm{el}}$, (terminal elimination rate constant) and $\mathrm{T}_{1 / 2}$, (elimination half-life).

Statistical analysis of all pharmacokinetic parameters was based on an ANOVA model. Dose proportionality was assessed for Test-1 in Stage 1 of the study.

\section{Safety assessments}

The safety parameters assessed included the occurrence of adverse events, the measurement of clinical laboratory parameters, vital signs, neurological function tests, physical examination and electrocardiogram (ECG) (See
Table 2 for the schedule of assessments). Clinical laboratory parameters (general biochemistry, endocrinology, hematology and urinalysis) were carried out in accordance with Standard Operating Procedures (SOPs) of the licensed laboratory of Laboratoires Bio-Médic. A list of the laboratory variables evaluated at screening and poststudy is provided in Table 3. For female subjects, pregnancy tests were also performed prior to the study, during the study and at post-study. Post-study tests were performed after the collection of the last blood sample of the study. Vital signs, ECGs, physical and neurological examinations were performed as described in the protocol. Descriptive statistics was applied.

\section{Statistical analysis plan}

The natural logarithmic transformation of $C_{\max }, \mathrm{AUC}_{\mathrm{T}}$ and $\mathrm{AUC}_{\infty}$ as well as the rank-transformation of $\mathrm{T}_{\max }$ was used for all statistical inference. Statistical analyses were generated using $\mathrm{SAS}^{\bullet}$ (version 9) using the Mixed procedure.

\section{Dose proportionality in stage 1}

In Stage 1 of the study a dose proportionality analysis was done on the main PK parameters $\left(C_{\max }, \mathrm{AUC}_{\mathrm{T}}\right.$ and AUC $_{\infty}$ ). These PK parameters were entered in a power model. The power model was defined as:

where $\alpha$ is the intercept, $\beta$ is the slope and $\varepsilon$ is the error term. A linear model with log-transformed dose as a

Table 2 Schedule of Assessments for both Stage 1 and 2

\begin{tabular}{|c|c|c|c|c|c|c|c|c|c|c|c|c|c|}
\hline \multirow[b]{2}{*}{ Days } & \multirow{2}{*}{$\begin{array}{l}\text { Pre-Trial } \\
-28 \text { to } 0\end{array}$} & \multicolumn{3}{|c|}{$\begin{array}{l}\text { Period } \\
1\end{array}$} & \multirow{2}{*}{$\begin{array}{l}\text { Wash- Out } \\
1-7\end{array}$} & \multicolumn{3}{|c|}{$\begin{array}{l}\text { Period } \\
2\end{array}$} & \multirow{2}{*}{$\begin{array}{l}\text { Wash-Out } \\
8-14\end{array}$} & \multicolumn{3}{|c|}{ Period 3} & \multirow{2}{*}{$\begin{array}{l}\text { End of Study } \\
16\end{array}$} \\
\hline & & 0 & 1 & 2 & & 7 & 8 & 9 & & 14 & 15 & 16 & \\
\hline Informed Consent Form Signed & $x$ & & & & & & & & & & & & \\
\hline Admission to Unit & & $x$ & & & & $x$ & & & & $x$ & & & \\
\hline Medical History & $x$ & & & & & & & & & & & & \\
\hline Physical Examination & $x$ & & & & & & & & & & & & $x$ \\
\hline Laboratory Tests & $x$ & $x$ & & & & $x$ & & & & $x$ & & & $x$ \\
\hline HIV Ag/Ac Combo, HBsAg (B) (Hepatitis B) and anti-HCV (C) Tests & $x$ & & & & & & & & & & & & \\
\hline Urine Alcohol and Drugs of Abuse Screening & $x$ & $X$ & & & & $x$ & & & & $x$ & & & \\
\hline ECG & $x$ & & & & & & & & & & & & $x$ \\
\hline Pregnancy Test & $x$ & $x$ & & & & $x$ & & & & $x$ & & & $x$ \\
\hline Vital Signs & $x$ & & $x$ & & & & $x$ & & & & $x$ & & $x$ \\
\hline Neurological Function Test & $x$ & & & $x$ & & & & $x$ & & & & $x$ & \\
\hline Drug Administration & & & $x$ & & & & $x$ & & & & $x$ & & \\
\hline Blood Sampling & & & $X$ & $x$ & & & $x>$ & $x$ & & & $x$ & $x$ & \\
\hline Adverse Event Monitoring & & & $x$ & $x$ & $x$ & $x$ & $x>$ & X & $x$ & $x$ & $x$ & $x$ & $x$ \\
\hline
\end{tabular}


Table 3 Laboratory safety assessments evaluated at screening and post-study

\begin{tabular}{|c|c|}
\hline $\begin{array}{l}\text { General } \\
\text { Biochemistry }\end{array}$ & $\begin{array}{l}\text { Sodium, potassium, chloride, glucose, urea (BUN), } \\
\text { creatinine, total bilirubin, alkaline phosphatase, AST, } \\
\text { ALT, albumin }\end{array}$ \\
\hline Endocrinology & Vitamin B12 and folic acid \\
\hline Hematology & $\begin{array}{l}\text { White cell, red cell, hemoglobin, hematocrit, MCV, } \\
\text { MCH, MCHC, RDW, platelets, MPV, neutrophil, } \\
\text { lymphocyte, monocyte, eosinophil and basophil }\end{array}$ \\
\hline Urinalysis & $\begin{array}{l}\text { Color, appearance, specific gravity, pH, leukocyte, } \\
\text { protein, glucose, ketones, bilirubin, blood, nitrite, } \\
\text { urobilinogen } \\
\text { Microscopic examination only performed if dipstick } \\
\text { test is positive for leukocyte, blood, nitrite or protein }\end{array}$ \\
\hline
\end{tabular}

continuous effect was fitted. A point estimate and a $90 \%$ confidence interval was derived for the slope $(\beta)$.

\section{Results}

Demographics

The demographics and baseline clinical characteristics for the volunteers for each stage of the study are listed in Table 4. Stage 1 was a single ascending dose study done in 8 male volunteers with a median age of 37 and median BMI of 24.77. Stage 2 was a 3-period study with a fasted cross-over comparison study of MSI-195 $\left(800 \mathrm{mg}\right.$ ) vs. Comparator (SAM-e Complete ${ }^{\mathrm{mm}}, 1600 \mathrm{mg}$ ) and a food effect period for MSI-15 (800 mg) in $19 \mathrm{fe}-$ males and 7 males with a median age of 33 and median BMI of 23.39.

\section{Tolerability and adverse events for stage 1}

For Stage 1, all 8 subjects received all 3 doses of MSI195. MSI-195 was well tolerated at all doses $(400,800$ and $1600 \mathrm{mg}$ ). The number of subjects experiencing adverse events (AEs) following administration of the $1600 \mathrm{mg}$ dose $(n=4 ; 50.0 \%)$ was greater than after administration of the $800 \mathrm{mg}(n=0 ; 0 \%)$ or $400 \mathrm{mg}(n=2$; $25.0 \%)$ doses. AEs that occurred at the $1600 \mathrm{mg}$ dose were primarily gastrointestinal (GI) and nervous system disorders, including abdominal pain, upper $(n=3)$, abdominal pain $(n=1)$, flatulence $(n=1)$, eructation $(n=$ $1)$, nausea $(n=1)$ and dizziness $(n=2)$. AEs that occurred at the $400 \mathrm{mg}$ dose level included abdominal pain $(n=1)$, flatulence $(n=1)$, abdominal discomfort $(n=1)$, dizziness $(n=1)$, cough $(n=1)$, upper respiratory infection $(n=1)$, feeling abnormal $(n=1)$, vessel puncture site pain $(n=1)$, blood pressure decreased $(n=1)$ and contusion $(n=1)$. By contrast, no AE was experienced at the $800 \mathrm{mg}$ dose levels of MSI-195.

For Stage 1, all AEs were considered by the investigator to be mild in intensity, with the exception of 1 event of upper abdominal pain, considered moderate in intensity in the $1600 \mathrm{mg}$ dose level. There were no serious AEs reported during this stage of the study, and no
Table 4 Demographic profile of patients for stages 1 and 2

\begin{tabular}{|c|c|c|}
\hline \multirow{3}{*}{ Age (years) } & \multicolumn{2}{|c|}{ Treatment Groups } \\
\hline & \multirow[t]{2}{*}{$\begin{array}{l}\text { Stage } 1 \\
N=8\end{array}$} & \multirow[t]{2}{*}{$\begin{array}{l}\text { Stage } 2 \\
N=26\end{array}$} \\
\hline & & \\
\hline Mean \pm SD & $34 \pm 9$ & $35 \pm 9$ \\
\hline Median & 37.0 & 33.0 \\
\hline Range & $21-44$ & $22-55$ \\
\hline Groups & n (\%) & n (\%) \\
\hline$<18$ & $0(0 \%)$ & $0(0 \%)$ \\
\hline $18-40$ & $5(62.5 \%)$ & 19 (73.1\%) \\
\hline $40-64$ & $3(37.5 \%)$ & 7 (26.9\%) \\
\hline $65-75$ & $0(0 \%)$ & $0(0 \%)$ \\
\hline$>75$ & $0(0 \%)$ & $0(0 \%)$ \\
\hline \multicolumn{3}{|l|}{ Sex } \\
\hline Female & $0(0 \%)$ & 19 (73.1\%) \\
\hline Male & $8(100)$ & 7 (26.9\%) \\
\hline \multicolumn{3}{|l|}{ Race } \\
\hline Asian & $1(12.5 \%)$ & $0(0 \%)$ \\
\hline Black & $1(12.5 \%)$ & $4(15.4 \%)$ \\
\hline Caucasian & $6(75.0 \%)$ & $22(84.6 \%)$ \\
\hline Other & $0(0 \%)$ & $0(0 \%)$ \\
\hline \multicolumn{3}{|l|}{ Weight (kg) } \\
\hline Mean \pm SD & $74.6 \pm 10.7$ & $64.0 \pm 11.6$ \\
\hline Median & 76.9 & 61.30 \\
\hline Range & $57.7-92.8$ & 48.4-98.0 \\
\hline \multicolumn{3}{|l|}{ Height (cm) } \\
\hline Mean $\pm S D$ & $175.3 \pm 10.1$ & $164.1 \pm 9.8$ \\
\hline Median & 175.25 & 161.25 \\
\hline Range & $158.5-189.0$ & 149.0-189.0 \\
\hline \multicolumn{3}{|c|}{ Body Mass Index $\left(\mathrm{kg} / \mathrm{m}^{2}\right)$} \\
\hline Mean \pm SD & $24.29 \pm 2.72$ & $23.63 \pm 2.28$ \\
\hline Median & 24.77 & 23.39 \\
\hline Range & $19.79-27.97$ & $20.15-28.29$ \\
\hline
\end{tabular}

subject experienced an $\mathrm{AE}$ that resulted in treatment discontinuation or withdrawal. No clinically important changes in laboratory values, vital signs, ECGs, or physical examinations were reported.

\section{Tolerability and AE's for stage 2}

For Stage 2, the twenty-six subjects were enrolled into a three-treatment, two-sequence, three-period crossover with food effect evaluation study to compare the safety and bioavailability of a single $800 \mathrm{mg}$ dose MSI-195 to that of commercially available SAMe at twice higher dose (1600 mg) level under fasted conditions. Following 
the completion of the cross-over design, subjects were administered a single $800 \mathrm{mg}$ dose of MSI-195 under fed conditions to evaluate the effect of a high calorie, high fat meal on the bioavailability and pharmacokinetics (PK) of MSI-195. Each subject received MSI-195 (800 mg) once under fed and once under fasting conditions. Twenty-four subjects completed all three treatment periods, which were separated by a 7-day washout.

There were no serious adverse events (SAEs) reported during this stage of the study. Two subjects were withdrawn. One withdrawn subject experienced an $\mathrm{AE}$ that resulted in treatment discontinuation (severe vasovagal reaction) in the first (fasted) period (after a $800 \mathrm{mg}$ dose of MSI-195) which resolved approximately $22 \mathrm{~h}$ post-dose, and one subject was withdrawn due to pregnancy prior to the second period (and after a dose of MSI-195). No clinically important changes in laboratory values, vital signs, ECGs, physical or neurologic examinations were reported. Twelve subjects experienced an $\mathrm{AE}$ in the MSI-195 fasted period, 11 subjects experienced an AE in the commercially available SAMe $1600 \mathrm{mg}$ reference group and 11 subjects experienced an $\mathrm{AE}$ in the MSI-195 fed group. AEs that occurred were primarily GI and nervous system disorders. Most AEs were mild in intensity. However, 3 subjects in the MSI-195 fasted period, 2 subjects in the SAMe Comparator (SAM-e Complete ${ }^{\mathrm{Tw}}$ ) period and 5 subjects in the MSI-195 fed period reported moderate AEs (abdominal pain, abdominal discomfort, headaches, dizziness). One subject reported severe $\mathrm{AE}$ of lower abdominal pain and presyncope in the MSI-195 fasted period. This subject was withdrawn from the study as noted above. AEs considered by the investigator to have a causal relationship with MSI-195 (fasted), SAMe reference (fasted) and MSI-195 (fed) were $72 \%, 82 \%$ and $100 \%$ respectively. All GI and nervous system disorders were considered related with the exception of 1 event of nausea and 1 event of dry lip.

Single-dose administration of MSI-195 at oral doses of $800 \mathrm{mg}$ was generally well tolerated in healthy adult volunteers. Adverse events were comparable to those of commercially available SAMe administered at oral doses of $1600 \mathrm{mg}$. The safety profile of single-dose MSI-195 did not appear to be altered by the consumption of a high fat, high-calorie meal, although the frequency of GI disorders was higher in the MSI-195 fasted period compared to the MSI-195 fed period (26.9\% vs $16.7 \%)$ and the frequency of nervous system disorders was lower in the MSI-195 fasted period compared to the MSI-195 fed period (11.5\% vs. $33.3 \%)$.

Most adverse events were considered treatment related. In Stage 1 of the study, 6 subjects experienced adverse events. Only one adverse event of vessel puncture site pain was considered non treatment related. In Stage 2 of the study, 8 subjects experienced treatment-related adverse events in the MSI-195 fasted period and 5 subjects experienced non treatment related adverse events. One event of nausea, dry lip, vessel puncture site reaction, and injury and 2 events of nasal congestion were considered not treatment related. In the MSI-195 fed period, all adverse events were considered treatmentrelated. See Table 5 for a summary of adverse events.

\section{Pharmacokinetic results-stage 1}

Following administration of MSI-195 by oral administration at doses of $400 \mathrm{mg}, 800 \mathrm{mg}$ or $1600 \mathrm{mg}$ to healthy volunteers approximately linear pharmacokinetics was observed based on mean plasma $C_{\max }, \mathrm{AUC}_{\mathrm{T}}$ and $\mathrm{AUC}_{0-\infty}$ (Table 6). The average pharmacokinetic curves for each period are shown in Fig. 1. The increase in AUC is close to, but slightly less than, doseproportional. The variability in parameters within groups may be responsible for this divergence from the expected relationship. The $\mathrm{AUC}_{\mathrm{T}}$ were $4643.9 \mathrm{ng} * \mathrm{~h} / \mathrm{ml}$, $9360.6 \mathrm{ng}^{*} \mathrm{~h} / \mathrm{ml}$ and $16,511 \mathrm{ng}^{*} \mathrm{~h} / \mathrm{ml}$ for $400 \mathrm{mg}, 800 \mathrm{mg}$ and $1600 \mathrm{mg}$, respectively. The elimination half-life showed some variability, potentially related to dose escalation, providing values $16.01 \mathrm{~h}, 8.87 \mathrm{~h}$ and $7.77 \mathrm{~h}$ for $400 \mathrm{mg}, 800 \mathrm{mg}$ and $1600 \mathrm{mg}$, respectively.

Large variability in the $T_{\max }$ was observed between the three dose levels and variability within groups was also high. Upon examination of the individual data sets it was observed that this variability may be related to delayed gastric emptying in specific subjects. Based on this data, a more stringent fasting schedule (from fasting for $1 \mathrm{~h}$ before dosing to $4 \mathrm{~h}$ before dosing) was used in Stage 2 of this study in an attempt to reduce the variability.

The low number of subjects $(N=8)$, coupled with the high variability of the data limits the ability to discern statistically significant differences amongst the treatment periods. An ordinary one-way ANOVA analysis of the three groups indicated that the area under the curve for the three groups were significantly different however, with a P value of 0.0107 and F score of 5.681. Multiple comparison analysis between groups (Tukey's multiple comparisons test) showed no significant difference between 400 and $800 \mathrm{mg}$ or between 800 and $1600 \mathrm{mg}$ (adjusted P values of 0.3952 and 0.1325 respectively) but did show a significant difference between the $400 \mathrm{mg}$ and $1600 \mathrm{mg}$ periods with a $\mathrm{P}$ value of 0.0082 .

\section{Pharmacokinetic results-stage 2}

The average pharmacokinetic profile for each of the 3 periods in Stage 2 is shown in Fig. 2. In Stage 2 of this trial, comparing fed and fasted in addition to comparison with the commercial SAMe formulation, the mean 
Table 5 Reported incidence of adverse events, by treatment group, by at Least 1 Subject Treated with MSI-195 or SAM-e Complete $^{\text {TM }}$ for stages 1 and 2

\begin{tabular}{|c|c|c|c|c|c|c|}
\hline \multirow[b]{2}{*}{ Body System/ Adverse Event } & \multicolumn{3}{|l|}{ Stage 1} & \multicolumn{3}{|l|}{ Stage 2} \\
\hline & $\begin{array}{l}\text { MSI-195 } \\
400 \mathrm{mg} \\
(\mathrm{N}=8)\end{array}$ & $\begin{array}{l}\text { MSI-195 } \\
800 \mathrm{mg} \\
(N=8)\end{array}$ & $\begin{array}{l}\text { MSI-195 } \\
1600 \mathrm{mg} \\
(N=8)\end{array}$ & $\begin{array}{l}\text { MSI-195 } \\
800 \mathrm{mg} \\
(\mathrm{N}=26) \text { Fasted }\end{array}$ & $\begin{array}{l}\text { SAM-e Complete }{ }^{\mathrm{TM}} 1600 \mathrm{mg} \\
(\mathrm{N}=24)\end{array}$ & $\begin{array}{l}\text { MSI-195 } \\
800 \mathrm{mg} \\
(\mathrm{N}=24) \mathrm{Fed}\end{array}$ \\
\hline Subjects with at least one AE [n(\%)] & $2(25.0)$ & 0 & $4(50.0)$ & $12(46.2)$ & $11(45.8)$ & $11(45.8)$ \\
\hline GASTROINTESTINAL DISORDERS [n(\%)] & $2(25.0)$ & 0 & $4(50.0)$ & $7(26.9)$ & $5(20.8)$ & $4(16.7)$ \\
\hline Abdominal Pain Upper [n(\%)] & 0 & 0 & $3(37.5)$ & 0 & 0 & 0 \\
\hline Abdominal Pain [n(\%)] & $1(12.5)$ & 0 & $1(12.5)$ & $2(7.7)$ & $1(4.2)$ & $2(8.3)$ \\
\hline Abdominal Pain, Lower [n (\%)] & & & & $1(3.8)$ & $2(8.3)$ & 0 \\
\hline Flatulence [n(\%)] & $1(12.5)$ & 0 & $1(12.5)$ & 0 & 0 & 0 \\
\hline Abdominal Discomfort [n(\%)] & $1(12.5)$ & 0 & 0 & $1(3.8)$ & $1(4.2)$ & $1(4.2)$ \\
\hline Abnormal Faeces [n(\%)] & 0 & 0 & 0 & 0 & $1(4.2)$ & 0 \\
\hline Dyspepsia [n(\%)] & 0 & 0 & 0 & $1(3.8)$ & 0 & 0 \\
\hline Lip Dry [n(\%)] & 0 & 0 & 0 & $1(3.8)$ & 0 & 0 \\
\hline Vomiting [n(\%)] & 0 & 0 & 0 & $1(3.8)$ & 0 & 0 \\
\hline Eructation [n(\%)] & 0 & 0 & $1(12.5)$ & 0 & 0 & 0 \\
\hline Nausea [n(\%)] & 0 & 0 & $1(12.5)$ & $4(15.4)$ & $2(8.3)$ & $1(4.2)$ \\
\hline NERVOUS SYSTEM DISORDERS [n(\%)] & $1(12.5)$ & 0 & $2(25.0)$ & $3(11.5)$ & $4(16.7)$ & $8(33.3)$ \\
\hline Dizziness [n(\%)] & $1(12.5)$ & 0 & $2(25.0)$ & $1(3.8)$ & $1(4.2)$ & 0 \\
\hline Somnolence $[\mathrm{n}(\%)]$ & 0 & 0 & 0 & $2(7.7)$ & $2(8.3)$ & $6(25.0)$ \\
\hline Headache [n(\%)] & 0 & 0 & 0 & $1(3.8)$ & $2(8.3)$ & $4(16.7)$ \\
\hline Dysgeusia [n(\%)] & 0 & 0 & 0 & 0 & $1(4.2)$ & $1(4.2)$ \\
\hline Presyncope [n(\%)] & 0 & 0 & 0 & $1(3.8)$ & 0 & 0 \\
\hline
\end{tabular}

MSI-195 $\mathrm{T}_{\max }$ was $4.50 \mathrm{~h}$ in the fasted state but was significantly delayed to $13.00 \mathrm{~h}$ in the fed state (Table 6). Administration of $800 \mathrm{mg}$ MSI-195 resulted in an average $\mathrm{C}_{\max }$ of $3280.8 \mathrm{ng} / \mathrm{mL}$ under fasted conditions and $1461.0 \mathrm{ng} / \mathrm{mL}$ when fed. The $\mathrm{AUC}_{\mathrm{T}}$ was $9434.4 \mathrm{ng} / \mathrm{ml}$ and $5224.7 \mathrm{ng} / \mathrm{ml}$ under fasted and fed conditions, respectively. After reaching $C_{\max }$, plasma levels of SAMe decrease relatively slowly, followed by a terminal-plasma elimination half-life $\left(\mathrm{T}^{1 / 2}\right)$ of $11.8 \mathrm{~h}$ under fasted conditions and $3.30 \mathrm{~h}$ under fed conditions. The delayed $\mathrm{T}_{\max }$ resulted in sub-optimal data for the calculation of the full elimination profile. This may have in turn affected the accuracy of the calculated PK parameters under fed conditions. PK parameters were generally quite variable, but the variability was comparable to the commercial formulation (SAM-e Complete ${ }^{\mathrm{mx}}$ ) of SAMe used as a comparator. On a per mg basis, MSI-195 under fasted conditions gave approximately threefold greater exposure than commercial SAMe as judged by $\mathrm{C}_{\max }$ (3.31-fold higher), $\mathrm{AUC}_{\mathrm{T}}$ (2.84-fold higher and $\mathrm{AUC}_{\infty}$ (2.80-fold higher). The $\mathrm{T}_{\max }$ for MSI-195 was somewhat shorter than seen with the commercial material.

Stage 2 of the study included 17 females and 7 males in the analysis. The descriptive gender analysis of the pharmacokinetic parameters (Table 7) indicated that gender appears to influence the mean $\mathrm{C}_{\max }$ value of both MSI-195 and SAM-e Complete ${ }^{\mathrm{Tx}}$ formulation and also had an impact on the AUC values. The bioavailability of MSI-195 was higher in males than in females as shown by a higher $\mathrm{C}_{\max }$ and $\mathrm{AUC}$. The reverse was observed with SAM-e Complete ${ }^{\mathrm{Tm}}$ where the bioavailability was greater in females (higher $\mathrm{C}_{\max }$ and AUC) than in males. The median time to reach the maximum plasma concentrations appeared to be slightly slower in female subjects, i.e. $1 \mathrm{~h}$ difference for both products. Finally, the half-life was similar in both male and female subjects.

The gender stratified descriptive analysis of the pharmacokinetic parameters showed that the female subjects had a higher $C_{\max }$ and AUC in fed conditions than males, and males showed higher $C_{\max }$ and AUC in fasting conditions than their female counterparts. Overall, the effect of food on the PK profile of MSI-195 was greater in males in terms of maximal concentrations and extent of absorption; their mean $\mathrm{C}_{\max }$ tripled and their mean AUC doubled in fasting conditions compared to fed. In both genders, $\mathrm{T}_{\max }$ was similar in both conditions.

Statistical analysis of MSI-195 at $800 \mathrm{mg}$ vs. SAM-e CompleteTM at $1600 \mathrm{mg}$, both under fasted conditions showed that the $\mathrm{AUC}_{\mathrm{t}}$ was significantly different as 
Table 6 Summary of pharmacokinetic parameters for S-Adenosylmethionine oral dosage forms for single dosing in Stages 1 and 2. Values are presented as the mean with the standard deviation (SD)

\begin{tabular}{|c|c|c|c|c|c|c|}
\hline \multirow[b]{3}{*}{ Study Stage 1} & \multicolumn{6}{|c|}{ Treatment } \\
\hline & \multicolumn{2}{|c|}{ MSI-195 400 mg } & \multicolumn{2}{|c|}{ MSI-195 800 mg } & \multicolumn{2}{|c|}{ MSI-195 $1600 \mathrm{mg}$} \\
\hline & & & & & & \\
\hline Variable & Mean & SD & Mean & SD & Mean & SD \\
\hline$C_{\max ,} \mathrm{ng} / \mathrm{mL}^{\mathrm{a}}$ & 1045.4 & 601.8 & 3255.5 & 2347.1 & 4808.8 & 4028.2 \\
\hline$T_{\max ,} h$ & 7.75 & 9.12 & 3.00 & 2.90 & 3.25 & 7.81 \\
\hline$A \cup C_{T}, n g h / m L$ & 4643.9 & 2519.2 & 9360.6 & 5338.9 & $16,511.0$ & $10,736.0$ \\
\hline$A \cup C_{\infty}, n g h / m L^{b}$ & 5322.1 & 956.1 & $10,633.2$ & 5147.3 & $16,454.2$ & $10,675.7$ \\
\hline $\mathrm{K}_{\mathrm{el}}, \mathrm{h}^{-1}$ & 0.0465 & 0.01 & 0.0886 & 0.04 & 0.1056 & 0.05 \\
\hline $\mathrm{T}_{1 / 2}, \mathrm{~h}$ & 16.01 & 4.90 & 8.87 & 3.08 & 7.77 & 3.26 \\
\hline \multicolumn{7}{|l|}{ Study Stage 2} \\
\hline & \multicolumn{2}{|c|}{ MSI-195 800 mg Fasted } & \multicolumn{2}{|c|}{ MSI-195 800 mg Fed } & \multicolumn{2}{|c|}{ SAMe 1600 mg Fasted } \\
\hline Variable & Mean & SD & Mean & SD & Mean & SD \\
\hline$C_{\max }, \mathrm{ng} / \mathrm{mL}$ & 3280.8 & 2383.8 & 1461.0 & 1153.7 & 1984.3 & 1430.0 \\
\hline$T_{\max ,} h$ & 4.50 & 1.72 & 13.00 & 6.03 & 6.00 & 1.23 \\
\hline $\mathrm{A} \cup C_{T}, \mathrm{ng} \mathrm{h} / \mathrm{mL}$ & 9434.4 & 5196.1 & 5224.7 & 3094.6 & 6643.8 & 3326.4 \\
\hline$A \cup C_{\infty}, n g h / m L$ & $10,025.5$ & 4799.5 & 7445.4 & 2688.2 & 7144.4 & 3214.2 \\
\hline $\mathrm{K}_{\mathrm{el}}, \mathrm{h}^{-1}$ & 0.1007 & 0.08 & 0.2322 & 0.07 & 0.0926 & 0.04 \\
\hline $\mathrm{T}_{1 / 2}, \mathrm{~h}$ & 11.47 & 7.66 & 3.30 & 1.37 & 9.27 & 4.59 \\
\hline
\end{tabular}

${ }^{\mathrm{a}}$ For $C_{\text {max }}$, the arithmetic mean is reported

${ }^{\mathrm{b}}$ For elimination parameters, $n=4$ for the $400 \mathrm{mg}$ dose, $n=7$ for the $800 \mathrm{mg}$ dose and $n=6$ for the $1600 \mathrm{mg}$ dose

indicated by a paired t test of all 24 completing subjects with a $\mathrm{P}$ value of 0.0180 . Note that the data were not dose adjusted. The $800 \mathrm{mg}$ of the MSI-195 was statistically significantly higher in $\mathrm{AUC}_{\mathrm{t}}$ compared with the $1600 \mathrm{mg}$ of SAM-e Complete ${ }^{\mathrm{nx}}$.

\section{Discussion}

The results of this study show that the relative bioavailability of the MSI-195 formulation of S-adenosylmethionine is 2.8 times higher than the comparator SAM-e Complete ${ }^{\mathrm{Tm}}$ product. In the cross-over, fasted portion of Stage 2, the $\mathrm{AUC}_{\mathrm{T}}$ for MSI-195 with an $800 \mathrm{mg}$ dose was $9,434.5 \mathrm{ng} \mathrm{hr} / \mathrm{mL}$ or $11.80 \mathrm{ng} \mathrm{hr} / \mathrm{mL}$ on a per $\mathrm{mg}$ basis. For the SAM-e Complete $^{\mathrm{Tw}}$ comparator, the $\mathrm{AUC}_{\mathrm{T}}$ with a $1600 \mathrm{mg}$ dose was $6,643.8 \mathrm{ng} \mathrm{hr} / \mathrm{mL}$ or $4.15 \mathrm{ng} \mathrm{hr} / \mathrm{mL}$ on a per $\mathrm{mg}$ basis. That data indicates a 2.8 fold higher relative bioavailability for the MSI-195 formulation.

In Stage 1, oral administration at doses of $400 \mathrm{mg}$, $800 \mathrm{mg}$ or $1600 \mathrm{mg}$ to healthy volunteers showed approximately linear MSI-195 SAMe pharmacokinetics based on mean plasma $C_{\max }, \mathrm{AUC}_{\mathrm{T}}$ and $\mathrm{AUC}_{(0-\infty)}$. The $\mathrm{AUC}_{\mathrm{T}}$ were $4643.9 \mathrm{ng} * \mathrm{~h} / \mathrm{ml}, 9360.6 \mathrm{ng} * \mathrm{~h} / \mathrm{ml}$ and 16 , $511.0 \mathrm{ng}$ "h/ml for $400 \mathrm{mg}, 800 \mathrm{mg}$ and $1600 \mathrm{mg}$, respectively. The elimination half-life showed some variability, potentially related to dose escalation, providing values $16.01 \mathrm{~h}, 8.87 \mathrm{~h}$ and $7.77 \mathrm{~h}$ for $400 \mathrm{mg}, 800 \mathrm{mg}$ and $1600 \mathrm{mg}$, respectively. Repeat dose studies of MSI195 have not been carried out at this time. Studies with other formulations of SAMe suggested that repeated dosing has no impact on SAMe exposure over time [12].

\section{Bioavailability comparison to literature}

Studies examining SAMe human pharmacokinetics have been published by several groups [12, 16-18]. While different methodologies used in these different studies are bound to lead to some anomalies, comparisons may be useful. The relatively high exposure on a per mg basis in comparing data with MSI-195 is immediately of note (Table 8 ). As discussed, MSI-195 provides approximately 2.8-fold greater exposure than commercial SAMe (SAMe Complete $^{\mathrm{Ts}}$ ) and a similar increase in exposure is seen relative to the data published by Yang et al. [12]. The study by Loehrer et al. achieved much lower exposure [17]. Intravenous and intramuscular administration of SAMe in these literature studies obviously achieved far higher plasma concentrations and, while the results from different studies are variable, some concordance is seen (See Table 8).

The sponsor has not carried out clinical studies to specifically estimate the oral bioavailability of MSI-195. 


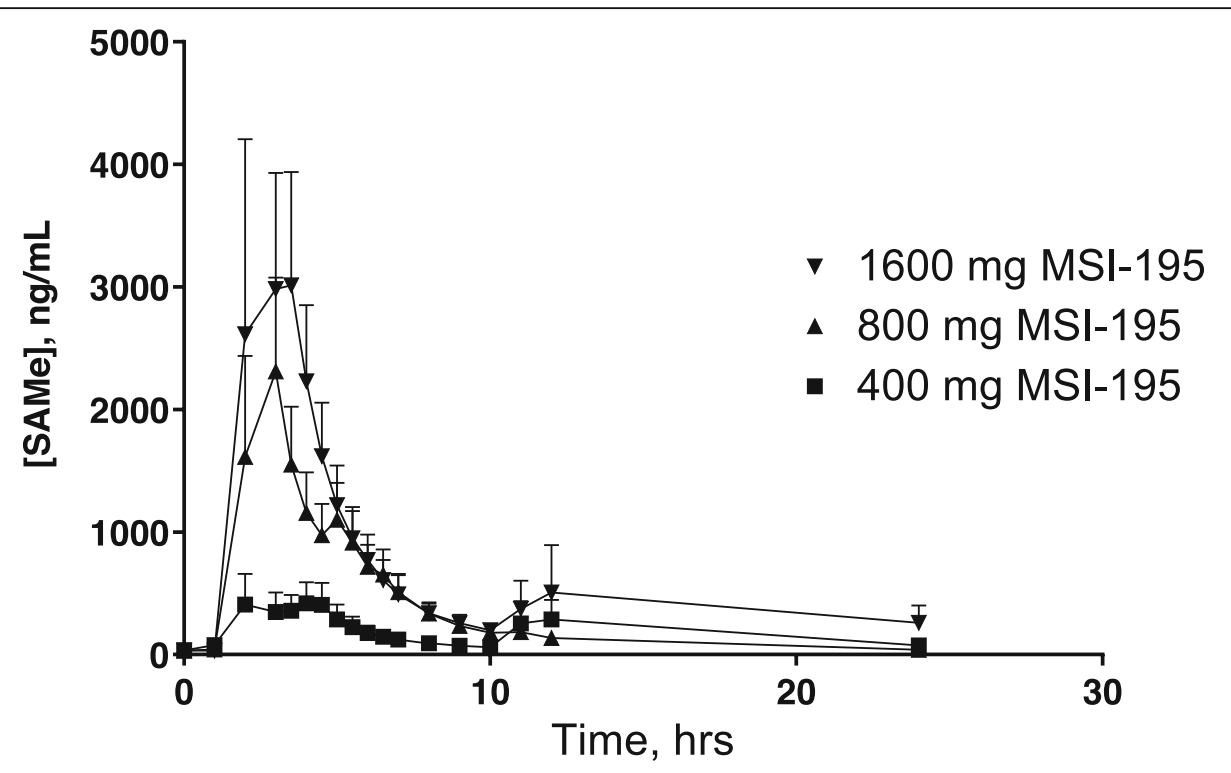

Fig. 1 Mean S-adenosylmethionine (SAMe) plasma concentration vs time profile following oral administration of $400 \mathrm{mg}$ (1 tablet), $800 \mathrm{mg}$ (2 tablets) or $1600 \mathrm{mg}$ (4 tablets) of the SAMe formulation MSI-195 to 8 fasted healthy male volunteers in Stage 1. Error bars are standard error of the mean

However, this can be estimated from literature that assessed intravenous administration of SAMe. By using the mean AUC from the four intravenous studies detailed in Table 8 , the oral bioavailability of MSI-195 (based on $1600 \mathrm{mg}$ in Stage 1) is approximately 9\%. Clearly this is a very approximate assessment of the absolute oral bioavailability. Comparative literature on absolute bioavailability for other formulations of Sadenosylmethionine is extremely limited. Yang and co- workers reported a oral to iv ratio of $2.6 \%$ and $2.14 \%$ for single and multiple oral dosing respectively [12].

\section{Food effect}

The $T_{\max }$ for enteric coated oral dosage forms is highly dependant on gastric emptying which is a stochastic event dependent on the density, size and shape of the dosage form, as well as the age, gender and fed state of the subject [19-21]. The pharmacokinetics of MSI-195

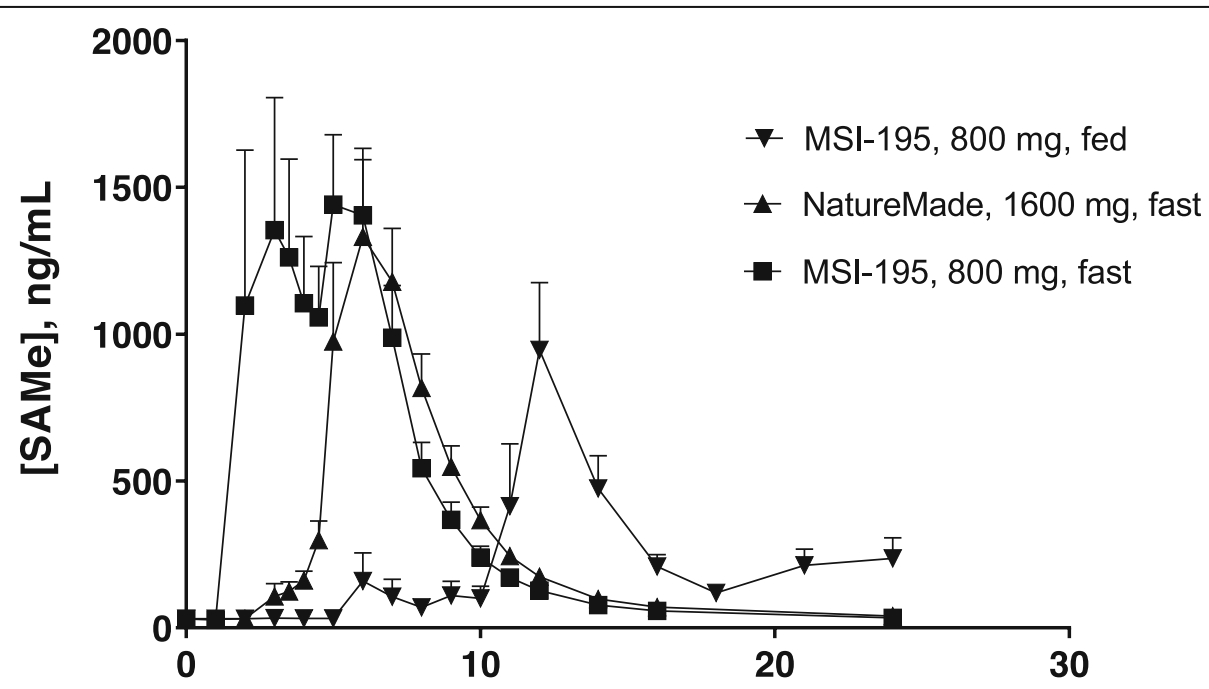

Fig. 2 Mean S-adenosylmethionine (SAMe) plasma concentration vs time profile following oral administration of 800 mg (2 tablets) of the SAMe formulation MSI-195 under fasted or fed conditions or 1600 mg (4 tablets) of SAM-e Complete ${ }^{\text {TM }}$ under fasted conditions to 24 healthy male and female volunteers in Stage 2. Error bars are standard error of the mean 
Table 7 Gender Effect Evaluation of S-Adenosylmethionine, Stage 2

\begin{tabular}{|c|c|c|c|c|c|c|}
\hline \multirow[t]{4}{*}{ PARAMETER } & \multicolumn{4}{|l|}{ MSI-195 } & \multicolumn{2}{|c|}{ SAM-e Complete ${ }^{\mathrm{TM}}$} \\
\hline & \multicolumn{4}{|l|}{$800 \mathrm{mg}$} & \multirow{2}{*}{\multicolumn{2}{|c|}{$\begin{array}{l}1600 \mathrm{mg} \\
\text { Fasting }\end{array}$}} \\
\hline & \multicolumn{2}{|l|}{ Fasting } & \multicolumn{2}{|l|}{ Fed } & & \\
\hline & Male, $(n=7)$ & Female, $(n=17)$ & Male, $(n=7)$ & Female, $(n=17)$ & Male, $(n=7)$ & Female, $(n=17)$ \\
\hline Cmax (ng/mL) & 3832.0 & 3053.9 & 1144.4 & 1591.3 & 1205.8 & 2304.9 \\
\hline Tmax (hours) * & 3.50 & 4.50 & 12.00 & 14.00 & 5.00 & 6.00 \\
\hline$A \cup C_{t}(n g \cdot h / m L)$ & 8693.5 & 8743.1 & 4599.2 & 5482.3 & 5098.7 & 7182.7 \\
\hline
\end{tabular}

with a high fat meal, including the delayed and variable $\mathrm{T}_{\max }$, are fully consistent with the well-studied pattern of gastric emptying of other enteric-coated tablets, for example, as reported in the FDA labeling for Depakote [22], EC-Naprosyn [23] and Voltaren [24]. This variable and extended delay with enteric-coated tablets given with food is typically attributed to variable gastric emptying of non-disintegrating dosage forms in the fed state. This variability in transit from the stomach to the GI tract is also evident in the fasted periods of this study. The $\mathrm{T}_{\max }$ for SAM-e dosage forms, which are all approximately $1 \mathrm{~g}$, enteric coated tablets is highly variable. This peak timing variability between subjects is the primary cause of the appearance of the "double peaks" observed on the average PK curves in Figs. 1 and 2.

\section{Gender effect}

Stage 2 of the study included 17 females and 7 males. Judging by the gender-specific pharmacokinetic parameters, it appears that gender may influence the mean $C_{\max }$ value of both MSI-195 and SAM-e Complete ${ }^{\mathrm{Tm}}$ formulation and also impact on the AUC values. The bioavailability of MSI-195 was higher in males than in females as shown by a higher $C_{\max }$ and AUC. The reverse was observed with SAM-e Complete ${ }^{\mathrm{Tm}}$ where the bioavailability was greater in females (higher $C_{\max }$ and $A U C$ than in males). The median time to reach the maximum plasma concentrations appeared to be slightly slower in female subjects, i.e. $1 \mathrm{~h}$ difference for both products. Finally, the half-life was similar in both male and female subjects.

Given the lack of consistent directionality to the gender effects observed in this study, the low number of subjects and the high variability of the pharmacokinetic properties for SAM-e formulations generally, more study would be required to draw reliable conclusions regarding gender effects for the studied formulations of SAM-e.

\section{Safety}

Single-dose administration of MSI-195 at oral doses of 400, 800 and $1600 \mathrm{mg}$ was well tolerated in healthy adult

Table 8 Dose corrected comparison of SAMe PK data across studies

\begin{tabular}{|c|c|c|c|c|c|c|c|c|}
\hline & \multirow[t]{2}{*}{ Reference } & \multirow[t]{2}{*}{ Route } & \multirow[t]{2}{*}{ Dose } & \multicolumn{3}{|c|}{ Parameters } & \multicolumn{2}{|c|}{ Parameters Corrected for Dose } \\
\hline & & & & $\mathrm{C}_{\max }$ & $\mathrm{AUC}^{\mathrm{a}}$ & $\mathrm{T}_{1 / 2}$ & $\mathrm{C}_{\max }$ & $\mathrm{AUC}_{\mathrm{T}}$ \\
\hline & & & & $\mathrm{ng} / \mathrm{ml}$ & $\mathrm{ng} / \mathrm{ml}^{*} \mathrm{~h}$ & $\mathrm{~h}$ & $(\mathrm{ng} / \mathrm{ml}) / \mathrm{mg}$ & $\left(\mathrm{ng} / \mathrm{ml}^{*} \mathrm{~h}\right) / \mathrm{mg}$ \\
\hline \multirow[t]{8}{*}{ MSI Study } & Stage 1: & & & & & & & \\
\hline & MSI-195 & Oral & 400 & 1045.4 & 4643.9 & 16.0 & 2.6 & 11.6 \\
\hline & MSI-195 & Oral & 800 & 3255.5 & 9360.6 & 8.9 & 4.1 & 11.7 \\
\hline & MSI-195 & Oral & 1600 & 4808.8 & $16,511.0$ & 7.8 & 3.0 & 10.3 \\
\hline & Stage 2: & & & & & & & \\
\hline & MSI-195 Fast & Oral & 800 & 3280.8 & 9434.4 & 11.5 & 4.1 & 11.8 \\
\hline & MSI-195 Fed & Oral & 800 & 1461.0 & 5224.7 & 33 & 1.8 & 6.5 \\
\hline & SAMe (NM) & Oral & 1600 & 1984.3 & 6643.8 & 9.3 & 1.2 & 4.2 \\
\hline \multirow[t]{7}{*}{ Literature Studies } & Loehrer et al. [17] & Oral & 400 & 144 & 489 & 1.7 & 0.4 & 1.2 \\
\hline & Yang et al. [12] & Oral & 1000 & 974 & 4748 & 6.2 & 1.0 & 4.7 \\
\hline & Yang et al. [12] & IV & 1000 & 67,600 & 162,000 & 4.1 & 67.6 & 162.0 \\
\hline & Guilidori et al. [16] & IV & 100 & 8320 & 7833 & 1.35 & 83.2 & 78.3 \\
\hline & Guilidori et al. [16] & IV & 500 & 31,300 & 42,500 & 1.68 & 62.6 & 85.0 \\
\hline & Stramentinoli et al. [18] & $\mathrm{IM}$ & 35 & - & 4300 & 1.35 & - & 122.9 \\
\hline & Stramentinoli et al. [18] & IV & 35 & - & 4000 & 1.35 & - & 114.3 \\
\hline
\end{tabular}


volunteers. Adverse events were comparable to those of commercially available SAMe administered at oral doses of $1600 \mathrm{mg}$. The safety profile of a single-dose MSI-195 did not appear to be altered by the consumption of a high-fat, high-calorie meal, although the frequency of GI disorders was higher in the MSI-195 fasted period compared to the MSI-195 fed period (26.9\% vs $16.7 \%)$ and the frequency of nervous system disorders was lower in the MSI-195 fasted period compared to the MSI-195 fed period (11.5\% vs. $33.3 \%)$. The most frequently observed adverse events experienced by subjects and judged to be possibly related to MSI-195 were gastrointestinal in nature. (see Table 5).

The severity of adverse events ranged from mild to severe during this study. Two (2) severe adverse events (abdominal pain lower and syncope) were observed on the same subject following the $800 \mathrm{mg}$ MSI-195 administration under fasting conditions. This subject was withdrawn from the study for safety reasons (Investigator's decision) following the vasovagal reaction.

No serious adverse events or deaths were reported during this study. No clinically significant effects on laboratory evaluations, ECGs, physical examinations or neurological function tests, were noted during this study. Following the single $400 \mathrm{mg}$ oral dose administration of MSI-195 one (1) subject experienced a clinically significant decrease in blood pressure at $2.50 \mathrm{~h}$ post-dose; the value came back within normal range after a few minutes.

In Stage 1 of the study (single ascending doses of MSI195), the highest rate of subjects reporting adverse events was observed with the highest dose of MSI-195 $(1600 \mathrm{mg})$, followed by the lowest dose $(400 \mathrm{mg})$. However, as no adverse event was reported with the intermediate dose $(800 \mathrm{mg})$. No clear pattern of increasing frequency of adverse events with increasing doses was observed during this study.

In the crossover periods of Stage 2, between MSI-195 $800 \mathrm{mg}$ and SAM-e Complete ${ }^{\mathrm{m}} 1600 \mathrm{mg}$ under fasting conditions, slightly more adverse events were reported with the administration of MSI-195 compared to the administration of SAM-e Complete ${ }^{\mathrm{mix}}$. However, this difference was mainly due to the multiple adverse events experienced by one subject (the subject with the vasovagal reaction mentioned earlier) following the administration of MSI-195. Thus, the safety profile of both products in fasting conditions appears more or less similar at the doses administered during this study.

In the food-effect evaluation on MSI-195 (in Stage 2), it was observed that fewer adverse events were reported when MSI-195 $800 \mathrm{mg}$ was administered under fed conditions compared to when it was administered under fasting conditions. Here again the same conclusion can be made as one subject (the subject with the vasovagal reaction mentioned earlier) experienced multiple adverse events when administered MSI-195 under fasting conditions. The observations made in this study lead to the conclusion that MSI-195 could be administered to patients in either fed or fasted conditions with a comparable safety outcome.

\section{Bioavailability enhancement}

The mechanism of bioavailability enhancement for MSI195 is directly related to the presence of propyl gallate. The molecular mechanism by which propyl gallate confers the higher bioavailability for SAMe disulfate tosylate is not known but may involve facilitating paracellular transport of SAMe [25]. MSI has observed in separate studies in beagles (data not shown) that propyl gallate needs to be co-formulated with SAMe in order to enhance systemic bioavailability. Given the basis of this selectivity for SAMe disulfate tosylate, concomitantly administered agents are not anticipated to exhibit increased absorption due to the presence of propyl gallate.

\section{Study limitations}

The sample sizes for both stages of this study were small, which is a limitation.

\section{Conclusions}

MSI-195 was well tolerated at single doses both with and without food, showed close to linear dose-dependant pharmacokinetics and demonstrated significantly higher relative bioavailability relative to the SAM-e Complete ${ }^{\text {Tx }}$ commercial comparator in a cross-over study as well higher relative bioavailability when compared to literature data.

\section{Abbreviations}

AE: Adverse event; $A \cup C \infty$ : Area under the plasma concentration versus time curve from time zero to infinity; AUCT: Area under the plasma concentration versus time curve from time zero to $24 \mathrm{~h}$; Cmax: Peak drug concentration; ECG: Electrocardiogram; Gl: Gastrointestinal; im: Intramuscular; iv: Intravenous; Kel: Terminal elimination rate constant; PK: Pharmacokinetics; SAE: Serious adverse event; SAMe: S-adenosylmethionine; SD: Standard deviation; SOP: Standard operating procedure; T1/2: Elimination half life; Tmax: Time to peak drug concentration

\section{Acknowledgements}

We would like to thank MSI Methylation Sciences Inc. who provided the funding for this study. We would also like to thank Marianne Rufiange, Fabio Garofolo and the team at Algorithme Pharma Inc. in Laval Quebec, Canada for their assistance in the conduct of this study

\section{Authors' contributions}

$B R C, L F$ and IDM all participated in the design and interpretation of the original study. IDM wrote the original draft. BRC, LF and IDM participated in review and editing. All authors read and approved the final manuscript.

\section{Funding}

This study was sponsored and funded by MSI Methylation Sciences Inc Officers of the funding body played a role in the design of the study, interpretation of the data and in writing the manuscript but played no role in the collection or analysis of the data. 


\section{Availability of data and materials}

The data generated and analyzed within this study is available from the corresponding author on request.

\section{Ethics approval and consent to participate}

Written informed consent was obtained from all individual participants before inclusion into the study. This study and all amendments were approved by the IRB "Institutional Review Board Services" Aurora, Ontario (now Advarra, Canada_IRB Rev 2013-FEB-26 HM/FG). Guidelines as drawn up by the institutional review board were followed regarding the treatment of human subjects in the study. These guidelines meet the requirements of the Declaration of Helsinki; they also meet the requirements of the United States Code of Federal Regulations (Title 21, Part 56), the Directive 2001/20/ EC (Europe) and the Tri-Council Policy Statement (Canada). This study was performed in compliance with Good Clinical Practice.

\section{Consent for publication}

Not applicable.

\section{Competing interests}

Beth Cameron and Ludvina Ferreira are former employees of MSI Methylation Sciences Inc. I. David MacDonald is an employee of MSI Methylation Sciences Inc. The study was sponsored and funded by MSI Methylation Sciences.

Received: 11 June 2020 Accepted: 26 November 2020 Published online: 14 December 2020

\section{References}

1. Bottiglieri T. S-Adenosyl-L-methionine (SAMe): from the bench to the bedside-molecular basis of a pleiotrophic molecule. Am J ClinNutr. 2002; 76(5):1151S-S1157.

2. Rutjes AW, Nuesch E, Reichenbach S, Juni P. S-Adenosylmethionine for osteoarthritis of the knee or hip. Cochrane Database Syst Rev. 2009;2009(4): CD007321.

3. Anstee QM, Day CP. S-adenosylmethionine (SAMe) therapy in liver disease: a review of current evidence and clinical utility. J Hepatol. 2012;57(5):1097-109.

4. Sharma A, et al. S-Adenosylmethionine (SAMe) for Neuropsychiatric Disorders: A Clinician-Oriented Review of Research. J Clin Psychiatry. 2017; 78(6):e656-67.

5. $\quad$ lisso CP, et al. S-Adenosylmethionine Affects ERK1/2 and Stat3 Pathways and Induces Apotosis in Osteosarcoma Cells. J Cell Physiol. 2016;231(2):428-35.

6. Liu Y, et al. S-adenosylmethionine induces apoptosis and cycle arrest of gallbladder carcinoma cells by suppression of JAK2/STAT3 pathways. NaunynSchmiedebergs Arch Pharmacol. 2020;393:2507.

7. Mahmood N, et al. Methyl donor S-adenosylmethionine (SAM) supplementation attenuates breast cancer growth, invasion, and metastasis in vivo; therapeutic and chemopreventive applications. Oncotarget. 2018; 9(4):5169-83.

8. Mosca $L$, et al. Effects of SadenosylLmethionine on the invasion and migration of head and neck squamous cancer cells and analysis of the underlying mechanisms. Int J Oncol. 2020;56:1212.

9. Targum SD, Cameron BR, Ferreira L, MacDonald ID. An augmentation study of MSI-195 (S-adenosylmethionine) in Major Depressive Disorder. J Psychiatr Res. 2018;107:86-96.

10. Targum SD, Cameron BR, Ferreira L, MacDonald ID. Early score fluctuation and placebo response in a study of major depressive disorder. J Psychiatr Res. 2020;121:118-25.

11. Stramentinoli G. Pharmacologic aspects of S-adenosylmethionine Pharmacokinetics and pharmacodynamics. Am J Med. 1987;83(5A):35-42.

12. Yang J, et al. Pharmacokinetic properties of S-adenosylmethionine after oral and intravenous administration of its tosylatedisulfate salt: A multiple-dose, open-label, parallel-group study in healthy Chinese volunteers. ClinTher. 2009;31(2):311-20.

13. De Berardis D, et al. A comprehensive review on the efficacy of S-AdenosylL-methionine in Major Depressive Disorder. CNS NeurolDisord Drug Targets. 2016;15(1):35-44.

14. Guan D, MacDonald ID. Compositions Comprising S-Adenosylmethionine and a Gallic Acid Ester, USPTO. United States: MSI Methylation Sciences Inc; 2015. p. 23.
15. Harrison N, MacDonald ID, Takacs-Cox A, Miller R. Pharmacokinetics of Sadenosylmethionine formulations USPTO. United States: MSI Methylation Sciences Inc; 2013. p. 32.

16. Giulidori P, Cortellaro M, Moreo G, Stramentinoli G. Pharmacokinetics of Sadenosyl-L-methionine in healthy volunteers. Eur J ClinPharmacol. 1984; 27(1):119-21.

17. Loehrer FM, Schwab R, Angst CP, Haefeli WE, Fowler B. Influence of oral Sadenosylmethionine on plasma 5-methyltetrahydrofolate, S-

adenosylhomocysteine, homocysteine and methionine in healthy humans. J PharmacolExpTher. 1997;282(2):845-50.

18. Stramentinoli G, Catto E. Pharmacokinetic studies of S-adenosyl-Lmethionine (SAMe) in several animal species. Pharmacol Res Commun. 1976;8(2):211-8.

19. Streubel A, Siepmann J, Bodmeier R. Drug delivery to the upper small intestine window using gastroretentive technologies. CurrOpinPharmacol. 2006;6(5):501-8

20. Davis SS, Hardy JG, Fara JW. Transit of pharmaceutical dosage forms through the small intestine. Gut. 1986;27(8):886-92.

21. Davis SS, Norring-Christensen F, Khosla R, Feely LC. Gastric emptying of large single unit dosage forms. J Pharm Pharmacol. 1988;40(3):205-7.

22. Abbott. Depakote medication guide. 2013.

23. Genentech. EC Naprosyn medication guide. 2010.

24. Novartis. Voltaren medication guide. 2011

25. McMillan JM, Walle UK, Walle T. S-adenosyl-L-methionine: transcellular transport and uptake by Caco-2 cells and hepatocytes. J Pharm Pharmacol. 2005;57(5):599-605.

\section{Publisher's Note}

Springer Nature remains neutral with regard to jurisdictional claims in published maps and institutional affiliations.

Ready to submit your research? Choose BMC and benefit from:

- fast, convenient online submission

- thorough peer review by experienced researchers in your field

- rapid publication on acceptance

- support for research data, including large and complex data types

- gold Open Access which fosters wider collaboration and increased citations

- maximum visibility for your research: over $100 \mathrm{M}$ website views per year

At $\mathrm{BMC}$, research is always in progress.

Learn more biomedcentral.com/submissions 